\title{
Proposta de organização dos conteúdos de ensino-treino dos esportes de raquete.
}

\section{Camila Cardoso*, Mairin Del Corto Motta, Larissa Rafaela Galatti.}

\section{Resumo}

Considerando os principais esportes de raquete (badminton, squash, tênis e tênis de mesa) o estudo teve como objetivo buscar as publicações sobre metodologias de ensino-treino e propor um novo modelo universal, pois os esportes de raquete continuam sendo ensinados, em grande parte, por metodologias analíticas e essas não asseguram que os problemas de ordem tática do jogo serão resolvidos.

\section{Palavras-chave:}

Pedagogia do Esporte, Proposta de ensino, Esportes de raquete.

\section{Introdução}

Os esportes de raquete continuam sendo ensinados, majoritariamente, através de metodologias analíticas (SILVA et al., 2017) focando nas técnicas e execução de movimentos repetitivos sem contexto de jogo, não deixando espaço para novas metodologias de ensino serem aplicadas. Considerando os principais esportes de raquete: badminton, squash, tênis e tênis de mesa (LEES, 2003), o objetivo do trabalho foi analisar, nas publicações científicas, artigos que propõe metodologia de ensino para os esportes de raquete e elaborar um modelo de organização de conteúdos de ensino-treino para os esportes de raquete de maneira universal.

\section{Resultados e Discussão}

Foi realizado o Estado da Arte sobre esportes de raquete nos periódicos indexados na Qualis Capes na área 21. Foram encontrados 207 artigos em revistas classificadas como B3 ou acima. Desses artigos, 16 foram classificados como metodologia de ensino de esportes de raquete.

Tabela 1. Publicações sobre metodologia de ensinotreino dos esportes de raquete.

\begin{tabular}{|l|l|l|l|}
\hline Qualis & Ano & $\begin{array}{l}\text { País do } \mathbf{1}^{\circ} \\
\text { autor }\end{array}$ & Modalidade \\
\hline A1 & 2001 & Finlândia & Badminton \\
\hline A1 & 2007 & EUA & Tênis \\
\hline A1 & 2007 & Austrália & Badminton \\
\hline A1 & 1999 & EUA & Multi \\
\hline A1 & 2007 & Irlanda & Badminton \\
\hline A2 & 1996 & EUA & Badminton \\
\hline A2 & 1996 & EUA & Badminton \\
\hline A2 & 2012 & EUA & Tênis de mesa \\
\hline A2 & 2001 & Espanha & Tênis \\
\hline B1 & 2010 & Brasil & Tênis \\
\hline B1 & 2007 & Polônia & Tênis \\
\hline B2 & 1981 & Colômbia & Tênis \\
\hline B2 & 1982 & Colômbia & Tênis \\
\hline B2 & 2017 & Brasil & Tênis de mesa \\
\hline B2 & 2014 & Brasil & Tênis de mesa \\
\hline B3 & 2007 & Brasil & Tênis \\
\hline N & antil & & and \\
\hline
\end{tabular}

Nos artigos encontrados, somente um engloba mais de um esporte de raquete em sua metodologia, o qual foi publicado em 1999, por uma revista A1 e tem seu autor com origem nos Estados Unidos da América.

A figura 1 demonstra a metodologia de ensino-treino Universal para esportes de raquete desenvolvida durante o projeto, que contém as seguintes palavras centrais: construir espaços (DEVIS, 1996 apud MENDEZ GIMÉNEZ, 2000; MITCHEL, OSLIN, 1999); tentar marcar o ponto (SIEDENTOP, 1990 apud GRIFFIN, 1996; MITCHEL, OSLIN, 1999); estabelecer posição (MENDEZ GIMENÉZ, 2000); defender espaços na quadra (MANDIGO, ANDERSON, 2003; MITCHEL, OSLIN, 1999); defender de um possível ataque (MENDEZ GIMENÉZ, 2000); resultados: ponto, erro forçado e erro não forçado.

Figura 1. Metodologia de ensino-treino Universal para esportes de raquete.

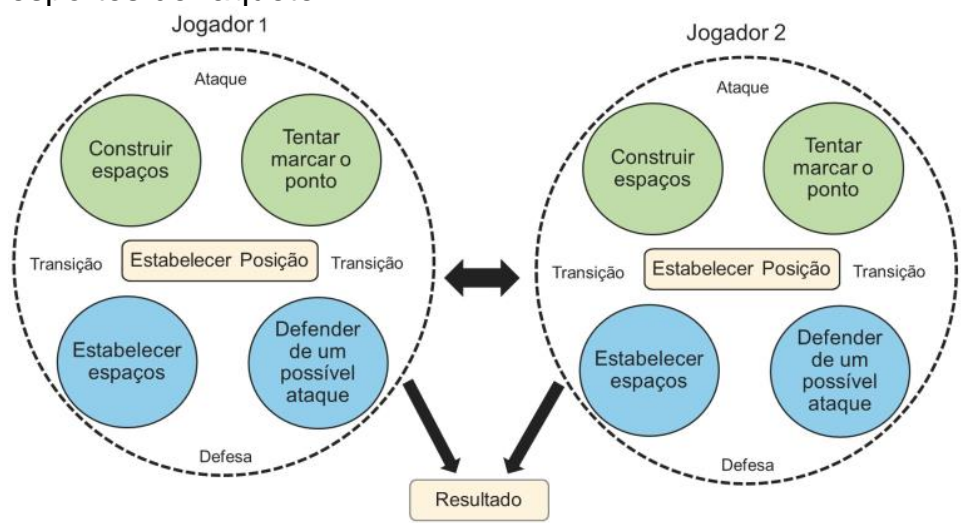

\section{Conclusões}

Há poucas publicações sobre metodologia de ensinotreino dos esportes de raquete, demonstrando a necessidade da nova proposta que trabalha os esportes de raquete de maneira universal.

\section{Agradecimentos}

Agradecemos ao CNPq pelo apoio ao projeto.

GRIFFIN, L. L. Improving Net/Wall Game Performance. Journal of Physical Education, Recreation \& Dance, v. 67, n. 2, p. 34-37, fev. 1996.

LEES, A. Science and the major racket sports: a review. Journal of Sports Science, v.21, n. 9, p. 707-732, set. 2003.

MANDIGO, J. L.; ANDERSON, A. T. Using the pedagogical principles in net/wall games to enhance teaching effectivenessTeaching Elementary Physical Education, 2003

MÉNDEZ GIMÉNEZ, A. Diseño e intencionalidad de los juegos modificados de cancha dividida y muro. Lecturas de Educación Física y Deportes, v. 18, n. $5,2000$.

MITCHELL, S. A.; OSLIN, J. L. An Investigation of Tactical Transfer in Net Games. European Journal of Physical Education, v. 4, n. 2, p. 162-172, 3 jan, 1999.

SILVA, J. V. P. DA et al. Família dos jogos esportivos com raquetes:

metodologia e procedimentos pedagógicos. Revista Brasileira de Ciência e Movimento, v. 25, n. 4, p. 5-12, 2017. 